This item was submitted to Loughborough's Research Repository by the author.

Items in Figshare are protected by copyright, with all rights reserved, unless otherwise indicated.

\title{
The rise and success of the barcode: some lessons for financial services
}

PLEASE CITE THE PUBLISHED VERSION

http://dx.doi.org/10.1057/jbr.2013.16

\section{PUBLISHER}

Springer (@ Palgrave Macmillan, a division of Macmillan Publishers Ltd 2013)

\section{VERSION}

AM (Accepted Manuscript)

\section{PUBLISHER STATEMENT}

This work is made available according to the conditions of the Creative Commons Attribution-NonCommercialNoDerivatives 4.0 International (CC BY-NC-ND 4.0) licence. Full details of this licence are available at: https://creativecommons.org/licenses/by-nc-nd/4.0/

\section{LICENCE}

CC BY-NC-ND 4.0

\section{REPOSITORY RECORD}

Milne, Alistair. 2019. "The Rise and Success of the Barcode: Some Lessons for Financial Services". figshare. https://hdl.handle.net/2134/24357. 


\title{
The Rise and Success of the Barcode: Some Lessons for Financial Services ${ }^{1}$
}

\author{
Alistair Milne ${ }^{2}$ \\ Loughborough University, School of Business and Economics
}

May, 2013

\begin{abstract}
This paper critically examines the analogy between the barcode and the standardization of data and communication in financial services, recounting the history of the barcode and considering what lessons this offers for regulation and management of financial firms. The initial development and uptake of the barcode was slow, requiring a decade before barcode scanning at point of sale fully took off worldwide and longer still for full application in the global supply chain. This experience indicates that even substantial economic and business benefits do not ensure rapid adoption of efficiency enhancing technological innovation. This requires incentives for adoption and these can remain weak until a demonstrable business case for change emerges. Such a case may be difficult to make for similar standardization in financial services, especially if adoption is perceived to lower barriers to entry and increase competition. (138 words)
\end{abstract}

JEL numbers: L14, G28

Keywords: business standards, data management, regulatory data, systemic risk assessment, technological change

Short biography: Alistair Milne is Professor of Financial Economics at Loughborough University School of Business and Economics. Previously he was for over twelve years senior lecturer and then reader in banking and finance at Cass Business School, City University of London. He has previously has worked at the Bank of England; the University of Surrey, London Business School, HM Treasury and for the Government of Malawi. He is the author of a comprehensive account of the global credit crisis The Fall of the House of Credit (Cambridge University Press, July 2009) and holds a $\mathrm{PhD}$ in economics from the London School of Economics. His principal current research interests are on the role of banks in the macroeconomy and on the implications of digital technology for financial services. He has published extensively on a variety of subjects, include financial systems and regulation, especially in relation to systemic financial risk; European sovereign debt; bank capital management and regulation; the impact of bank balance sheets on monetary transmission; and financial infrastructure and technology especially in the areas of post-trade processing and payment systems. 


\section{Introduction.}

The barcode is the world's most familiar business standard. We use regularly it as consumers scanning items at supermarket checkouts. But the barcode is far more than this. Since its first commercial point of scale application in the early 1970s, the barcode and related standards have become indispensible tools for the management of global supply chains, providing previously unimagined transparency about the location and progress of goods and materials; play an essential role in the safe and effective delivery of pharmaceuticals, blood and other health care services and are finding applications in a very wide range of other businesses. Can similar standardization achieve a parallel transformation of financial services? Could such developments provide effective tools for monitoring and mitigating systemic financial risk?

To address this question Sections 2 and 3 of this paper describe the development of the barcode and related standards and their subsequent internationalization. Section 4 then reviews some of the efforts at similar standardization in financial services, looking at the FIX protocol, at SWIFT messaging standards and at the current proposed new regulatory standard for legal entity identification, the Global LEI. Finally the concluding Section 5, following the lead offered by the recent speech of Andrew Haldane, executive director for financial stability at the Bank of England, assesses the lessons from the barcode for financial services and in particular the question of whether a similar standardization can assist current efforts to monitor and mitigate systemic financial risk. ${ }^{3}$

While agreeing with Haldane on the huge potential business benefits from a similar standardization in financial services as that which has already taken place in the retail and supply chain industries, and the potential this offers for more effective monitoring of systemic financial risk, the more detailed review of the history of the barcode provided here suggests a degree of caution. There are considerable barriers to adoption of global standards in financial services. The parallel with the barcode is not exact. A regulatory driven approach to imposing global standards - without the full engagement of shareholders and without addressing the substantial and challenging change of changing culture within the financial services firms to focus less on short term profits on more on long term benefits to customers and shareholders - is unlikely to reap all of the available benefits.

\section{Origins of the barcode and its initial US adoption}

A standout event in the history of the bar code took place at 8.01am on June 26, 1974 at a Marsh's supermarket in Troy, Ohio. This was when, Sharon Buchan, 31 year old check out assistant, scanned a 10 pack of 50 sticks of Wrigley's juicy fruit gum using a laser scanner and sold it for 67 cents, the first time an item was scanned and then sold at point of sale. 
Figure 1: An EAN barcoding

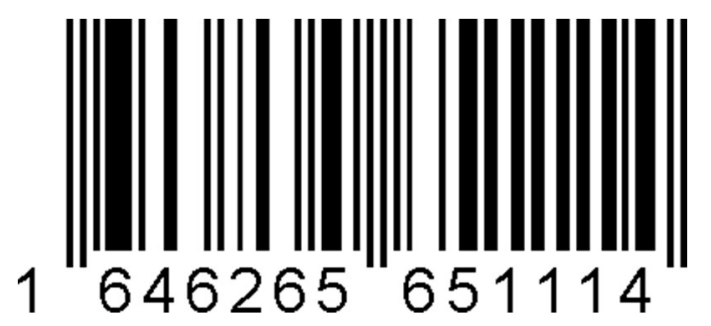

\begin{abstract}
An example of a 13-digit EAN number coding (a standard international article number, originally European Article Number). It inherits the 'two block' structure of the original UPC-A encoding of the 12-digit UPC number, but uses Laurer's parity system to encode an additional character by varying the parity of the left half of the symbol, thus enabling it to encode all thirteen digits (printed below the barcode) plus a final additional check-sum digit.
\end{abstract}

The first two sections of this paper take the story of the barcode, both backward in time before the first commercial barcode scanning 1974 and forward to today. It should first be pointed out that barcodes (such as the one illustrated in Figure 1) are data carriers, standards for the electronic capture of information on physical items using laser scanning, but the business application of the bar-code depended on the parallel development of identification standards, for identifying products and subsequently (for use in the supply chain) shipments, locations and entities; and for their more recent supply chain application on the development of communication standards for the exchange of information between computer systems (notably the XML language but also specific standards tailored for use in the supply chain). The following account outlines the joint evolution of data capture, identification and communication standards in the history of the barcode.

While technical proposals and patents for automated checkout processing go back to the 1930s, the technology eventually used for this first scanning has its roots a quarter century before the transaction in Troy, in the late 1940s. Then two graduate students - Bernard Silver and Joseph Woodland - at the Drexel Institute of Technology in Philadelphia took up a challenge posed by the chief executive of a local retailing chain to develop a system to automatically read product information during checkout. They experimented with different approaches, but eventually settled on a system of pattern recognition, with thick and thin lines, analogous to the dots and dashes of Morse code. In 1952 they patented the first bar code system, for both linear and 'bulls-eye' (circular) barcodes. ${ }^{4-5}$

Barcoding did not however find any immediate commercial application. One barrier to widespread use was that the bar-coding needed to be accompanied by a system of numerical product identification i.e. a further accompanying standard. This emerged in the late 1960s and early 1970s when an initiative of the National Association of Food Chains NAFC in the US led to the development of the 'Universal Grocery Produce Identifier', which later became the widely used 11 digit Universal Product Code UPC. This code consists of an initial category digit (for general grocery applications this is 0 ), a 5 digit code representing the manufacturer and a further 5 digit code representing the product. 
Advances in computing and scanning technologies was making the possibility of automated checkout and subsequent storage of information an attractive commercial possibility. But a reliable process for printing and then reading these codes was needed. For two years between 1971 and 1973 committees from the US grocery industry, with advisory support from McKinsey, established (demanding) product specifications and considered the choice of the appropriate symbol for automated scanning. The leading proposal, amongst more than a dozen commissioned, was that of RCA who used a version of the Silver-Woodland 'bulls-eye' bar code (RCA had actually purchased the patent before its expiry in 1969). This technology though was technically flawed, the most notable problem that 'running of ink' in the printing process could make the bar code indecipherable. ${ }^{6}$

Eventually, in March 1973 the UPC symbol selection committee adopted a rival technology that more effectively supported reliable point of sale scanning. This was the now ubiquitous linear 'UPC-A' barcode system developed by a team at IBM - led by Laurer with Woodland as a member - which encoded the 11 digit UPC code using the now familiar linear barcode used at point of sale worldwide, with an additional twelfth check digit and 'guard Bars' at the beginning, middle and end of the code to facilitate scanning.

The success of the UPC-A barcode over its rivals was due to a number of technical features (these are described in Appendix D of the reminiscences of the IBM engineer responsible for several of these technical innovations). ${ }^{7}$ Printing in the direction of the lines avoided the decipherability problems that undermined the RCA technology. 'Omni directional reading' of the IBM linear barcode- a requirement of the symbol selection committee that the bar code should be readable from any angle - was achieved by using two right-angled mirror at point of sale, ensuring that a scanner would always be able translate the bar code regardless of the orientation with which it was presented. ${ }^{8}$

An elegant economy in the footprint of the bar code (which was required to be no more than $1 \frac{1}{2}$ square inches) was achieved by coding the full 12 digit number (including the check digit) as two independently read 6-digit numbers each of which was printed as small (nonsquare) block, separated by a quiet space. In today's world of low cost high performance computing such technical details matter less, but in the mid-1970s they were crucial to achieving an effective solution.

Despite an effective technology coming onto the market in the mid-1970s, the take-up of bar coding at point of sale was at first relatively slow. Manufacturers had to be persuaded to place the new coding on their products. The original laser scanning systems were expensive. ${ }^{9}$ The purchaser of the ten pack of Wrigley's chewing gum in 1974 was Clyde Dawson, the research and development manager at Marsh's supermarkets. Without the enthusiasm of individuals like Dawson and of supermarket owner Robert Marsh for technological experiment, regardless of immediate commercial payoff, initial efforts at developing point of sale scanning might never have taken place when they did.

But the potential for commercial payoff was critical for adoption. Eventual takeoff was driven by the finding that the benefits were actually much larger than originally anticipated. An unfavourable balance of cost against perceived benefits meant that by 1977 only around 200 stores in the US had point of sale scanning facilities. But research by IBM with these early adopting clients, published as their Automation Benefits Study, revealed surprisingly large commercial returns on investment, with an estimated return on equity of $51 \%$ (a audio interview with Bill Selmeier author of this research gives many examples of the benefits; his 
book tells this story in more detail). ${ }^{10-11}$ Much of these benefits came from the communication of detailed sales information to management, allowing them for example to discover the impact of small price changes on sales volumes. ${ }^{12}$ Realisation of the large benefits from point scale scanning led to rapid adoption; by 1980 some 8,000 stores a year in the US were adopting UPC-A scanning.

\section{Internationalisation and the transformation of the supply chain}

The next stage of bar code adoption was internationalization. There was strong and growing interest from other countries in the initial US efforts to develop automated bar code scanning. By 1976 this had led to the proposal of an extended numbering system, the 'International Article Number' or EAN (originally developed as a European Article Number, hence the acronym, but adopted worldwide), which extended the US UPC number by adding a further initial digit. Combined with the initial category number, and sometimes with the first character of the 5 digit manufacturing code, EAN could be used to identify the country of origin. Work on EAN encouraged international co-ordination of identification standards, with the creation of the Universal Code Council in the US and of EAN international (a representative body for various national product identification bodies.)

Laurer at IBM, through clever use of redundancy in the UPC-A symbol, was able to adjust the algorithms for converting UPC-A symbol into a human readable decimal number so that the 13 digit EANs could be encoded and read without any alteration of the UPC-A standard or any need to update installed UPC scanners. ${ }^{13}$

Two further significant developments extended the reach of EAN in 1980. The first - of great significance to the academic community - was the allocation of the initial location codes 978 and 979 to an imaginary nation Bookland, serving as the country of origin for all published books; thus was the familiar ISBN number born with an immediately scannable bar code representation. The second, critical for subsequent application, was agreement in 1988 by the Universal Code Council/EAN on a new standard EAN-code 128 for the tracking of goods and consignments in the supply chain. This code has a similar linear representation as UPC-A and EAN, but could support 48 alpha-numerical elements, instead of 12 (or 14) numerical digits. EAN-code 128 was not useable for rapid scanning at point of sale, since it did not support omni-directional reading or offer the same small footprint as UPC-A and EAN. Its impact was opening up a whole new chapter of bar code applications in monitoring of the supply chain both domestically and internationally.

This standardization, together with the adoption of that humble but crucial component of the global supply chain the shipping container, underpins modern international trade. ${ }^{14}$ In the subsequent 30 years companies have come to rely on electronic recording and communication to provide extraordinary visibility of their global supply chains.

Consignments can now be tracked by location and interventions - initial orders, response to delays, financing and payments - can carried out promptly and appropriately. The 
consequence has been a transformative, reducing costs and delays and radically improving quality standards.

For all this to happen a number of different developments had to come together. Some of these required a hitherto unknown degree of co-ordination amongst the many national bodies that, as a result of the spread of the point of sale barcode, had taken responsibility for business identification standards (GS1 provide a fuller overview). ${ }^{15}$ These international standards include:

- Identification numbering standards. These include:

i) the Global Shipping Container Code (SSCC) first introduced in the 1980s, which is used to identify uniquely and cartons, pallets and packages as well as containers;

ii) the family of Global Trade Item Numbers (GTIN), of which EAN/UPC is one, allowing unique identification of all products and services through the supply chain and at point of sale.

iii) the Global location number (GLN) which identifies both locations (which can be as specific as a shelf in a warehouse), legal entities (for example the division of a company) or a function such as an accounting department.

- Data carriers suitable for electronic reading, of which the UPC-A and EAN Code 128 have been the most important; but there are other carriers including RFID (radio frequency identification tags) which is especially useful in supply chain applications because it can be used to read a number of items of a single pallet and increasingly widely used data matrix (2-dimensional) barcodes suitable for use both at point of sale, in the supply chain and also for interpretation by mobile phones. These carry far more information than the traditional linear bar codes.

- Communication standards exploiting the spread of internet communication and the use of XML mark up to support seamless communication of supply chain information within and between organizations.

Many of these standards are now supported globally by GS1, a federation of national business standards bodies (see http://www.gs1.org/ ), formed by the 2005 merger of Universal Code Council and EAN authority, and co-ordinated by a Brussels based global office, which prepares voluntary global standards, including the barcode, that have been adopted in a number of industries, notably retailing, healthcare and transport and logistics.

Figure 2: Branding of the GS1 supported standards
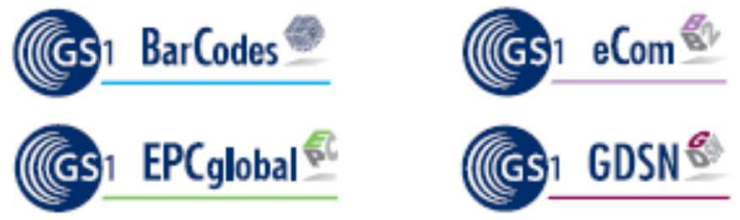
The four key groups of standards supported by GS1 each have their own visual branding (see Fig 2). In addition to barcodes, GS1 supports the EPC global standards into microchip recognition, the GDSN global identity standards, and eCom standards for business to business communication

Global industry standards such as those supported by GS1 have not been as fully adopted in all industries, in the same way as they have been in retail, supply chain and healthcare. In other industries, e.g. automobile or aircraft manufacturing, it is more common to find that major companies have developed proprietary systems of standards for their own products and components. This is not to say that standards are not crucially important, for example the sophisticated fault reporting and maintenance systems that keep modern airliners in skies depend crucially on identification standards for aircraft components, but there is no obvious business reason for say Boeing and Airbus to share common standards. Another example of a widely used proprietary standard is in armed forces supply, with the Pentagon - the US defense administration - imposing its own system of standards on all suppliers to the US armed forces. These examples indicated that agreement on and adoption of global or industry wide standards is not always easily achieved.

A central feature of GS1 is that is a federation of operationally separate national GS1 organisations. Many of these national GS1 bodies, while now adopting a common name emphasizing their participation in global standard setting, originated independently in response to the need for support of local retail bar-code standards. Much of the work of these national GS1 bodies is now around overseeing training and education of local users in the application of GS1 standards. Where there is demand from a local industry they may also establish their own local business standards (provided these do not conflict with the global GS1 standards). A good example comes from the German automotive industry, where the different companies have agreed local GS1 standards for spare parts (source personal communication). The resulting quality improvement and cost reductions provides German manufactures with a competitive edge over their non-domestic rivals.

Standardisation was only one aspect of dramatic change in supply chain management over the past thirty years. A entire business discipline 'supply chain management' has also emerged. In 1996 a global body - the Supply Chain Council -- devoted to improving professional standards in supply chain management was created, and now has over 1,000 corporate members. There is also now an entire industry supplying global logistic services. Supply chain management has become staple fare on MBA and other business degrees with a number of standard textbooks. ${ }^{16}$

One aspect of supply chain management, of relevance to financial stability, is the control of the so-called 'bull whip' effect, a situation in which initial order fluctuations from the final consumers, are amplified down the supply chain. ${ }^{17}$ Information technology has played a key role in controlling the bullwhip effect, with the insight that stability is supported by close monitoring and accurate transmission of current consumer demand, instead of relying on 
mechanical forecasts that can extrapolate disturbances. Thus electronic communication and the standards that support them are crucial for promoting supply chain stability.

Another major application of bar code scanning has been in health services. At an early stage it was recognized that bar codes and bar code scanning could provide invaluable control over the use of pharmaceuticals and other health care products, ensuring the correct product is used and correct dosage applied. This is another example of a slow beginning followed by eventual take-off, this time however driven by regulators. Despite the introduction of bar code systems for health care, initial take up was slow. Only after February 2004, when the US Food and Drug Authority introduced a requirement that all medications must have bar codes (and in 2005 on accredited blood products), did adoption take off.

\section{Experience in financial services}

Having recounted the history of bar-coding and its spread into the supply chain and other industries, this section discusses the related experience of standardization in financial services. Three examples from financial services are reviewed here: the FIX protocol, SWIFT messaging standards and the current effort to establish a global system of legal entity identifiers (or LEI) for use in wholesale financial markets.

The FIX protocol is an open messaging standard, maintained by the not-for-profit body FIX Protocol Ltd, and used for trading level and some post-trade communications among brokers, investment managers and trading platforms. There is no charge for the use of FIX, although a large number of vendors sell trading and asset management software that is based on FIX.

FIX was first developed and piloted in 1992-1993 as a joint initiative between the US brokerdealer Salmon Brothers and one of their major clients Fidelity investments, as a means of standardizing the flow of messaging for equity market orders and trade execution. ${ }^{18}$ The FIX initiative quickly attracted interest from a range of participants, first in New York equity markets and little more than a year later in London, both from buy side institutions such as Fidelity and from sell side broker dealers. By January 1997 the highly successful FIX protocol version 4.0 was launched. ${ }^{19}$ This and successive versions of FIX are now the well established standard formats for pre-trade messaging in equity markets around the world.

A consultancy study by OXERA reviews the benefits of FIX and the challenges to its wider adoption. ${ }^{20}$ Direct benefits flow to FIX users from lower connectivity costs (a single interface can be used to connect with many different brokers or clients) and from reduced costs and operational risks. Even more important however may be the indirect benefits that arise when a large proportion of firms in a market have adopted the protocol, allowing connectivity to be maintained with a larger numbers of brokers or clients, leading in turn to more choice and increased competition. Increased competition in turn puts pressure on 
brokers to deliver better quality services, e.g. improved execution strategies or access to new trading technologies. Finally potential further efficiency gains may be realized when a large proportion of firms adopt messaging standards, including standardized reporting of trading activities and exposures, reduced costs of complying with regulatory requirements and more efficient execution of post-trade processes.

Interviews reported by Oxera confirm that FIX has played a crucial role in supporting competition between traditional exchanges and new trading platforms, both in the US and in Europe, and in supporting the growth of automated 'algorithmic' trading. This has in turn - through contraction of fees and bid-ask spreads in equity markets - resulted in substantial reduction in transaction costs for end-investors. However Oxera also point out the challenges to further adoption of standardized messaging in global financial markets. Outside of global equity markets because many of the direct private benefits of automated message flow have already been achieved, albeit with relatively fragmented systems and approaches that differ from one firm or one market to another. There is therefore relatively little private incentive to adopt FIX more fully across the full range of wholesale financial market activities. The indirect benefits of greater use of FIX in foreign exchange, fixed income and derivative markets and in post-trade, while very substantial, are public not private and so provide relatively little adoption incentive for individual firms. ${ }^{21}$

Similar lessons emerge from the history of SWIFT. This is recounted by Scott and Zachariadis who describe SWIFT's activities as follows 'SWIFT is responsible for providing the platform, products and services that allow member institutions to connect and exchange financial information.'22 SWIFT, then called the Society for Worldwide Interbank Financial Telecommunications, was established in 1973 as a collective owned by 239 banks from fifteen countries, established in order to address the inefficiencies of sending international payment instructions via Telex (Telex is short for teleprinter exchange, the now archaic but one widely used 1950s technology for transmission of printed message via telephone lines, much as telephones are used for audio communication.) As reported by Scott and Zachariadis these Telex payment instructions were sent in free text format, and as many as ten separate messages might be required in order to deal with ambiguities and complete a single payment instruction. SWIFT commenced operationally in 1977, with the introduction of the SWIFT network, providing an much more efficient communications platform that could send instructions 'within a minute of being entered'. The key benefit however was the 'automation of the standardized authentication and data entry processes' that were responsible for many of the delays in telexed payment instructions.

As Scott and Zachariadis document the standardization introduced by SWIFT emphasized backwards compatibility with the older Telex based payment instructions, simply because during these early years many banks were not on the SWIFT network. The benefits of standardization therefore depended on being able to choose, between sending the same standardized message either by Telex or through the SWIFT network. Thus SWIFT simply 
adopted identification codes (SWIFT codes) that were based on the Bank Identifier Codes already used for Telex payment instructions.

During the 1980s SWIFT introduced several technical developments: providing standard connections to the SWIFT network known as 'SWIFT interface devices' or SIDs; introducing a network with distributed processing capability (SWIFT II) that could cope with much greater volume of traffic; and most interestingly SWIFT messaging standards were adapted for use in other applications, for example internal communication within major banks and most importantly for messaging in the securities industry under the International Standards Organization standard ISO7775. In the early 2000's this was replaced by the more flexible ISO15022. SWIFT was given management responsibility for maintaining these standards.

SWIFT has grown enormously over the years. Scott and Zachariadis Table 2 report that the number of members rose from 238 in 1973 to 8468 in 2008 (despite the very substantially increased concentration of the banking industry over these years through mergers and acquisitions), while the number of messages per annum increased from 3.4 million in 1977 to 3.5 billion in 2007 . This has led to increasing governance challenges, as summarized by Scott and Zachariadis: 'What started as a focused project to solve a relatively bounded set of immediate problems subsequently grew into a community of practice and eventually began to be regarded as a cartel with control over the possibility for innovation in networks and standards in the sector.' For example SWIFT has been accused by corporate treasurers of serving the interests of its member banks and obstructing developments in standards that might better serve the needs of corporate customers, for example through creating the possibility of greater competition in the provision of cash management services through direct non-bank access to the SWIFT network.

The most recent effort at establishing standards in financial services has been a regulatory initiative, the global 'legal entity identifier' or LEI annnounced by the Financial Stability Board. ${ }^{23}$ This is intended to provide a unique numerical identifier for every participant in wholesale financial markets. In the vision of Andrew Haldane, together with the further establishment of a standardized global systems of instrument or product identifiers (PI), LEI is intended to provide the basic ingredients - the nouns and adjectives - for a common financial language that in turn can be used to provide complete transparency of financial transactions and exposures, similar to that achieved in the global supply chain. ${ }^{3}$ The institutional and legal arrangements for LEI are due to be put in place by the second quarter of 2013, and an interim LEl system is already being developed in New York markets (by the US securities depository and clearing body DTCC together with SWIFT) for the registration and clearing of over the counter derivative positions, as required by the Dodd-Frank act.

A distinguishing feature of LEI, making it very different from the barcode or the successful establishment of FIX protocol and SWIFT, is that the impulse for establishing this new standard has come not from the industry in response to a perceived business need; but rather from the recognition by regulators that the problems of the recent global financial 
crisis were made worse by fragmented information systems and the inability of firms to aggregate positions (most obviously in the case of the failure of Lehman Brothers International because few market participants had any accurate measure of their exposure to the bankruptcy, let alone of the exposure of other market participants). Potentially the LEI could yield substantial reductions in both operational costs and risk in many aspects of wholesale market trading, but this is not certain. Whether it does so depends critically on its successful adoption as a universal standard, which as the history of the barcode indicates may not take happen until a persuasive business case emerges.

\section{Conclusion: lessons for financial services}

The first and encouraging lesson for financial services from the rise and success of the barcode (and associated identification and communication standards) is that it illustrates the great potential for cost and risk reduction in business to business (B2B) processes, when common industry standards are established.

Some of the greatest potential for cost and risk reduction comes from reduced costs of the processing and exchange of information. This is especially obvious in wholesale markets and international payments. The FIX protocol has allowed substantial cost reductions in pre-trade communication in equity markets, avoiding the necessity for buy side firms to maintain a set of multiple bespoke interfaces to route orders to their brokers. In international financial transactions the dramatic rise in the volume of SWIFT messages, and corresponding ease of transmitting secure instructions for payments and security instruments, testifies to the substantial efficiency gains built on SWIFT messaging standards.

While these have been substantial gains, the full potential for cost-efficiency gains in financial services from standardization of data remains far from fully exploited. To mention two examples, post-trade processing (clearing and settlement) continues to be plagued by trade failures where discrepancies in the information held by the two sides of the trade mean that the trade cannot be completed. For example one common cause of trade failure is inaccurate information on the identity of the ultimate customers (this often happens when several trades are packaged together as a single transaction) in turn requiring a time consuming manual intervention to reconcile the information held by buyer and seller and allow final settlement. Standardisation of data, such as the LEI, promises to eliminate most such trade failures and lead to genuine 'straight through' processing of investment transactions. Information problems also interfere with the settlement of derivative contracts, especially if obligations move from one entity to another either through sale or transfer.

The potential for cost and risk reduction goes much further than this, through the possibility of a 'quantum leap' in the transparency of financial firms. The speech by Bank of England Executive Director Andrew Haldane has rightly emphasized these benefits, addressing the considerable shortcomings in the information available to both regulators and investors. ${ }^{3}$

One example of many from the global financial crisis has been the great difficulty banks have faced in working out their own exposures to various types of problem loans. When asked by regulators 'What is your holding of securities of type $X$ or your lending to group of customers $Y$ ? How are these sub-portfolios performing?' the usual response was that no immediate answer could be given. 
Answering such questions required a time consuming and expensive information retrieval exercise, with a lot of manual intervention or special coding.

The following exchange, from Oral Evidence given to a committee of the UK Houses of Parliament, gets to the heart of the matter: ${ }^{24}$

'Chairman (Peter Lilley): On the question of information, should the power to obtain data be modelled on the US Office of Financial Research? As a related question, you once said, Governor, that you did not want to impose onerous obligations on banks to provide endless information every day but you want them to be in a position to have the data so that when you phone up to ask, "How much Greek debt do you have?" they can answer without having to spend three weeks looking for it. Do you need any powers to ensure that banks have the information?

Sir Mervyn King: The PRA can do that; they have the powers. It is important to go down a route where we do not say to the banks, "You must send us this data every three months", and nothing is ever taken off the list. During the crisis, and even quite recently, when we wanted information it turned out that the regulators did not have data relevant to the problem at hand. It is a different approach to data collection. It is trying to get away from the provision of a lot of routine information, management reports and detail, which has no relevance to the PRA and no one would ever look at, and focusing on the stuff that we ought to look at. Rather than burdening the banks with a massive data reporting requirement, we should make it clear to them, "We think you ought to know the answers to the following questions, and from time to time we will want to know the data, too, but do not send it to us until we ask for it." One of the changes in the culture of the supervisors that we are trying to bring about is to get them to think about the data they require to do their job, not take from their drawer a long list of questions they have been given and tick or not tick the boxes but sit down and say, "What do I need to know about this bank to judge whether or not it is too risky?" It will take a long time to change that culture, but those are the kinds of people we are committed to growing, developing and turning into effective supervisors.

Andrew Bailey: From time to time we do it now. I do it in running supervision. We say, "We want this by close of business tomorrow." Sometimes I get protests from chief executives of banks and I say to them, "Look, I'm not asking you for anything you should not have yourself to run your business.'

Thus the situation during the crisis, and this is still largely true today, is that senior management of firms were typically unable to retrieve timely and accurate information on their own exposures.

The situation is even worse when it comes to the data required for monitoring and dealing with systemic financial risk. Every firm in wholesale and retail financial markets, use their own proprietary standards, so that even when firms are able to provide information to regulators on their exposures, regulators are not in a position to aggregate this information in any meaningful way. An acknowledged major shortcoming of financial regulation prior to the global financial crisis was that it ignored risks to the financial system as a whole, in particular the potential for systemic impact from the failure of firms such as AIG or the monoline insurers providing protection in the credit default swap market; or the wide range of institutions engaged in 'shadow banking' i.e. maturity mismatch 
outside of the regulated banking sector pursued with very limited capital. When Lehman Brothers failed it turned out that neither regulators nor individual firms had any clear idea of what exposure they had to Lehman or to other large systemically important firms. Little has fundamentally changed. Today, even though regulators are now alert to the potential build-up of systemic risk, they still do not have to tools for measuring and monitoring such systemic risks.

Underlying all these informational retrieval difficulties has been a combination of old systems and fragmented standards. Many bank processes rely on old legacy information systems in operation for twenty five years or more, with only limited operational flexibility (they were designed to do a few things, such as credit or debit accounts, accurately; and have only limited further functionality). This problem is exacerbated by a plethora of different data standards within larger institutions, an inheritance of decades of growth through acquisition. In any particular market area larger banks can have ten or twenty or even more legacy systems, doing essentially the same tasks, that do not communicate well with each other. Such messy arrangements were not planned, they are simply the byproduct of mergers and acquisitions and the development of incompatible solutions in different regions and jurisdictions. ${ }^{25}$

Uniform industry wide standards could address these inefficiencies. They could also yield further benefits, for example allowing outside stakeholders, both regulators and investors, to compare the positions of different institutions and summarize these positions at institutional and industry level. The ability to trade risky securities, including securitized assets, would also be greatly enhanced by common industry standards that allow purchasers to be fully informed about what is being sold. There are thus a wide range of evident benefits to having uniform industry standards across financial services, similar to the barcode and other GS1 standards in retail, supply chain and healthcare.

The second, and more sobering lesson for financial services, is the great challenge to achieving widespread adoption of standards, at either firm or industry level. It is far from being enough just to create a standard, it has to be used, and for this to happen firms need incentives for adoption. Uptake can be slow, even in the case of the barcode this took several years, and may never happen at all, especially if adoption does not suit the private interests of individual firms.

The experience of financial services indicates that, while standards have been adopted at global level by most participants in some particular markets and types of transaction, the adoption of standards many other aspects of financial services has been limited. FIX, while extended to provide functionality in other markets and in the post-trade environment has not become the dominant tool for communication that it is in equity market order and execution. SWIFT is essential in some contexts, in particular international payments and securities transaction messaging, but is by no means a universal standard. The uptake and application of LEI remains untested and unclear.

A further reason for weak adoption incentives are the costs of replacing old legacy systems. The cost of change is not just purchasing new hardware and software, it is the herculean task of converting all existing loan and investment records to the new standards (this can explain why most successful examples of standards adoption in financial services - FIX and SWIFT messaging - have all been about addressing critical inefficiencies in potentially profitable transaction processing, not addressing lack of functionality in the recording and management of exposures). 
All this suggests that the rise and success of the barcode in retail point of sale and supply chain management was due to a combination of circumstances that cannot be easily replicated in financial services. The barcode and related standards, having eventually achieved widespread use in point of sale application, provided a relatively direct means for achieving cost and risk reduction in domestic and global supply chains. Individual firms had a strong interest in imposing uptake of standards on their suppliers, to lower costs and improve reliability of delivery and quality of supply.

The availability and further development of the new global numbering, data carrying and communication standards (now managed under the auspices of GS1) reinforced and intensified the trend towards standardization and transparency of the supply chain. Suppliers who did not adopt these standards could not compete with those that did. Purchasers that did not fully exploit supply chain inefficiencies were at a market competitive disadvantage. Incentives were strongly aligned towards adoption of standards and continuous improvement of supply chain standards.

This makes clear that the analogy between the barcode in retail and supply chain and the various communication, identification and product standards in financial services is not an exact one. For individual firms in many, although not all, financial markets and financial transactions, the cost and efficiency benefits of standardization are not nearly large enough to outweigh the potential threat to revenues from increased competition. The virtuous circle found in the supply chain -- of development and adoption of standards in the supply encouraging more development and adoption - is not present in most areas of financial services.

While the examples of FIX and SWIFT illustrate that the benefits in terms of cost and risk reduction can justify widespread adoption, this is not always the case. In many markets, for example foreign exchange or government bonds or OTC derivatives, that are dominated by a handful of dealers, increased competition is a vital threat that could threaten profits margins in sales and trading. The incentives on individual firms to engage in process standardization and transformation are therefore much weaker. This in turn suggests that the achievement of the large potential gains of standardization identified by Haldane are going to require a much more conscious industry wide effort than has been necessary for the rise and success of the barcode in retail, supply chain and health care.

Two further lessons may be mentioned. The relative weakness of these private incentives can explain why the LEI, an essential component of global standardization in financial services, has been a regulatory rather than an industry initiative. But a purely regulatory driven process is in danger of eventually foundering if it cannot overcome the challenge of weak private incentives for adopting common data standards by individual firms. Data quality and data management remains a low priority for management and shareholders. The 'Chief Data Officer' or equivalent position is of far lesser seniority than the Chief Financial Officer or even the Chief Risk Officer. No annual report of any financial firm pays any attention to issues of data quality or data management. Yet the quality and relevance of the risk and accounting information that is highlighted in these reports depends, ultimately, on the availability of adequate data - the problem of 'garbage-in garbage-out' is hardly addressed. Moreover the lengthy statements in every annual report about how firms value their customers and place customer service at the heart of their operations are meaningless without ensuring the quality of data that actually allows firms to do this in any practical way. 
Issue of data management and data quality matter for all firms, but especially so in financial services, because the healthy functioning of the rest of the economy depends on financial intermediaries and financial markets transferring resources from savers to finance productive investment at relatively low additional cost for their services; and providing the insurance and risk management to customers at reasonable but not excessive charges. These services are essential to enable nonfinancial companies and other borrowers to pursue all available positive net present value investment opportunities.

In practice financial services firms like many publicly traded companies are not focused on serving customers, but instead on achieving short term profits, by imposing high fees and a high interest rate margins and keeping costs as low as possible. This means that they hold back from the investments that can allow them to better identify investment opportunities and or more accurately quantify risks and they resist, as far as possible, any standardization that will reduce barriers to entry from new competitors. This approach will not deliver the economic growth that investors demand and our economies need. In the longer run it undermines the financial returns to financial services firms themselves. Shareholders thus need to be persuaded that it is in their best interests that management of financial firms embrace the opportunities offered by standardization of data and focus on the long term benefits that this can achieve.

For this reason the full exploitation of the benefits of LEI and subsequent PI (product identification standards) will require an intensive engagement with shareholders in financial services firms, encouraging them to take the wider view and pressing for changes in the companies they own, and in particular prioritizing the necessary investments in data standards and data information, necessary for delivering improved services to corporate, retail and institutional investor customers.

Finally, a comment on the business culture of financial services, it is striking how much of the initial development of the barcode depended not on financial reward, but simply on a spirit of adventure and a commitment to finding better ways of getting things done. Yes, financial incentives matter, but the story of the rise and success of the barcode provides a clear rebuttal of the widespread perception in the financial services industry that the contribution of employees to business success is solely motivated by and can only be achieved by offering wildly generous financial rewards. On the contrary, as the personal biographies of the early barcode pioneers testify, truly valuable technological and business innovation, such as the developments that underpinned the transformation of the global supply chain are typically the work of relatively modestly paid individuals motivated primarily by the fascination and satisfaction of their work. It is difficult to deny that financial services would be much improved industry - for customers, investors and employees alike - if such attitudes were more widespread.

\section{Notes}

1. I am grateful to comments from two anonymous referees and from audiences at the 2012 SIBOS conference in Osaka, the Bank of England Centre for Central Banking Studies January 2013 conference on regulatory data, and also to George Laurer for correcting some 
technical misunderstandings. Any remaining errors and omissions are my responsibility alone.

2. email: a.k.I.milne@lboro.ac.uk

3. Ali R., Haldane A.G., Nahai-Williamson P. Towards a Common Financial Language, text of speech to Securities Industry and Financial Markets Association, NY. Bank of England; 2012. p. 21.

4. US Patent \#2,612,994, October 7, 1952.

5. The story of this first barcode patent is recounted in several places including Wikipedia

6. To use the language of network economics, this running of ink was a classic installed base' problem, due to the age of much of the machinery used for printing of packaging. One major supplier - Miller's Beers of Milwaukee - was in 1974 still using a 1908 printing press. Laurer G.J. Engineering Was Fun. self published; 2007.

7. Laurer's autobiography should be required reading for anyone in the human resource function of our major financial institutions. His life story is a great example of how much skilled engineers contribute - both to their employers and to society as a whole - in return for modest pay and without requiring aggressive 'performance incentives'. His business and social contribution is clearly far greater than any investment bank employee, for a financial reward only a fraction of what our modern 'quants' and financial traders think of as their due.

8. This particular innovation was due to Laurer and can still be seen inside of today's supermarket scanning equipment.

9. The story of the first commercial scanners developed by Spectra-Physics, now Dealogic Scanning, in the early stages of bar code scanning is recounted by their president Bill Parnell (Parnell B. Bar Code Scanning - The Conception of an Industry. Datalogic Scanning. 2009. Available from: http://www.varsguide.com/additional-information-on-the-anniversary-ofthe-barcode/). The scanner used at Troy's supermarket weighed 112 pounds, cost $\$ 56,880$ in 2009 prices, had an operating life of only two years, and required a physical widening of the six checkout lanes at Marsh's supermarket in order to accommodate the bulky new equipment.

10. Selmeier B. Bill Selmeier discusses Creating the FMI Grocery U.P.C.Scanning Benefits in 1977 [Internet]. You Tube Audio. 2010. Available from: http://www.youtube.com/watch?v=ZUn7KPjR3ic

11. Selmeier B. Spreading the Barcode. Self published; 2009. p. 298.

12. The most striking example reported by Selmeier is that many early adopters found that small increases in the price of their own-brand orange juice, far from reducing sales, often led to higher purchase volumes because customers associated higher price with better 
quality. POS scanning offered a wealth (in both the figurative and literal sense of word) of information about micro-demand that could then be commercially exploited.

13. See Appendix D of Laurer's autobiography for technical details including the use of 'odd' and 'even' parities for this purpose.

14. On the role of the shipping container see Levinson, M. (2006). The box: How the shipping container made the world smaller and the world economy bigger. Princeton: Princeton UP.

15. See GS1. The Value and Benefits of the GS1 System of Standards. Available from: http://www.gs1.org/docs/GS1 System of Standards.pdf

16. These include Hugos M.H. Essentials of Supply Chain Management, Third Edition. Wiley; 2011. and Myerson P. Lean Supply Chain and Logistics Management. McGraw-Hill Professional; 2012.

17. Lee H.L., Padmanabhan V., Whang S. Information Distortion in a Supply Chain: The Bullwhip Effect. Management Science. 1997 Apr 1;43(4):546-58.

18. FixProtocol. Fix History as of 2001. 2001. Available from: www.fixprotocol.org/documents/647/fix history 20010221.ppt

19. FixProtocol. Financial Information Exchange Protocol (FIX) Version 4.0. 1997.

20. OXERA. What are the benefits of the FIX protocol? Oxford, UK; 2009 p. 68.

similar divergence between private and public benefits arises in retail payments innovation.

21. See Milne A. What is in it for us? Network effects and bank payment innovation. Journal of Banking \& Finance. 2006;30(6):1613-30.

22. Scott S. V., Zachariadis M. Origins and development of the global SWIFT network. 2010.

23. FSB. A Global Legal Entity Identifier for Financial Markets. 2012. Available from http://www.financialstabilityboard.org/publications/r 120608.pdf

24. Bailey A, King M, Tucker P. Uncorrected Oral Evidence Taken before the Joint Committee on the Draft Financial Services Bill. London: Hansard; 2011. p. 29.

25. The information in this and subsequent paragraphs comes from an ongoing research project on the application of the global LEI system. 